\title{
GENOCIDIO LISTO PARA SENTENCIA
}

\author{
Luis Peraza PARgA* \\ Alicia KERBER PALMA**
}

Por primera vez, la Corte Internacional de Justicia, CIJ, entendió de un contencioso en el que el Estado demandado sufrió una transformación profunda en su formación, estructuras y constitución. Fue un auténtico cambio de régimen que cumple, si no los supera ampliamente, los elementos necesarios identificados por Morlino: normas, autoridad y valores nuevos.

En el lapso de trece años, pasó de ser la República Federal de Yugoslavia a Serbia y Montenegro, ${ }^{1}$ y finalmente, simplemente Serbia. Además, al ser un caso de genocidio, el primero al que es sometido un Estado dentro del principio de jurisdicción voluntaria internacional, la Corte aplicó el derecho internacional humanitario y de derechos humanos para resolver si poseía jurisdicción para juzgar, y, como así ha sido, alcanzar a finales de febrero del 2007 una resolución que debió haber sido un invaluable instrumento de la verdad histórica, y previsiblemente una cascada de millones de dólares en indemnización a Bosnia.

Siempre se descontó que no terminaríamos 2006 sin esta sentencia. ¿Por qué ahora? Cuando el estatus final de Kosovo está más lejos que nunca porque las posturas de independencia y de autonomía limitada son irreconciliables, espoleadas por las declaraciones de Bush en junio de 2007 sobre su necesaria independencia y la contraréplica de Putin. Diez meses de deliberación, después de dos meses y medio de audiencias públicas y catorce años de proceso. Diecisiete magistrados dedicados por completo con sus correspondientes equipos de juristas para discernir si

* Maestro en cooperación internacional y doctorante en derecho constitucional en la Universidad Complutense de Madrid.

** Miembro del servicio exterior mexicano.

1 Montenegro accedió como el estado número 47 al Consejo de Europa el 11 de mayo del 2007, después de un referendo sobre su independencia ganado por estrecho margen en mayo del 2006 y una declaración formal como nueva nación unos días después. 
Serbia era responsable internacionalmente de cometer genocidio contra la población no serbia de Bosnia Herzegovina. La ley internacional aplicable es el Convenio sobre Genocidio que data de 1949, y que es de obligado cumplimiento para todos los países y funcionarios. Cuando se presentó la demanda, era el único instrumento legal, después apareció la base jurídica para el Tribunal Penal Internacional para la Antigua Yugoslavia TPIAY, ${ }^{2}$ y en 1998, el Estatuto de Roma que crea la Corte Penal Internacional.

Los llamados acuerdos de Dayton, propiciados y forzados por Clinton en lo que quizás fue su mayor éxito de política internacional, la pacificación de los países que surgieron de la fragmentación cruenta de una nación, la muerte natural de los más destacados líderes radicales, las sentencias y condenas de los responsables individuales de los crímenes contra la humanidad ocurridos en aquella zona desde 1991, por parte del TPIAY y de las salas nacionales de los países afectados, bien por remisión de aquél o por propia iniciativa. Un mes después de interpuesta la demanda, la Corte emite medidas provisionales, ratificadas en julio de ese mismo año, dirigidas a Serbia para que cese y prevenga cualesquiera actos de genocidio contra musulmanes u otro grupo racial, étnico, nacional o religioso. En 1997, Serbia logra que la Corte acepte parecidas alegaciones contra Bosnia, y pasados cuatro años las retira. Durante casi dos meses, cien horas de testimonio oral, se suceden las audiencias públicas con declaraciones de víctimas y expertos no revelados al público hasta fecha posterior, y catorce años después, emerge el veredicto final de imposible apelación salvo el extraordinario de revisión ante la misma Corte, descartándose el de interpretación, porque la sentencia es todo menos oscura.

Los argumentos de la demandante se basaron en que al no ser una corte penal, la gran fotografía es la que cuenta a la hora de establecer la responsabilidad de Serbia en el genocidio. Es la política de Estado la relevante, no la intención de sus líderes. Es la naturaleza repetitiva de esos actos, las circunstancias y la manera en las que se dieron, la vastedad geográfica de la destrucción, su naturaleza sistemática.

2 En junio del 2005, los presidentes de Serbia y Montenegro, Croacia y Bosnia Herzegovina emiten una declaración conjunta en la que parecen comprometerse a cooperar con este Tribunal, facilitar el retorno de todos los refugiados y desplazados a sus hogares, asegurar la protección de las minorías y eliminar el régimen de visados entre ellos. 
La defensa se centra en las supuestas incorrecciones, la falta de relevancia y de valor probatorio de los hechos alegados en los informes internacionales de los diferentes órganos investigadores de Naciones Unidas, de las organizaciones no gubernamentales, de las informaciones de prensa, ya que ninguno alcanza la fiabilidad de una prueba obtenida de manera creíble, interrogando a personas directamente relacionadas con los hechos por jueces expertos y experimentados en casos con sobre abundancia de información, aceptado por las partes y que desde su publicación no hayan sido controvertidos. La defensa ha estimado que las cifras de asesinados alegadas por la parte demandante han sido muy abultadas, hasta diez veces su número real. La dura fiscal del TPIAY, con nombre de actriz pero apariencia lejana, Carla del Ponte, está convencida de la participación de Serbia en la guerra en Bosnia al establecer el apoyo incondicional a un criminal internacional, presunto genocida, todavía en fuga, Mladic antes, durante y después, todavía hoy, de la guerra civil que descompuso la Yugoslavia de Tito. La Corte le concede que Serbia no ha cooperado plenamente con ella y su tribunal, y que por ello ha violado las obligaciones que emanan de la Convención de Genocidio.

Para los efectos de demostrar lo esencial de contar con los expedientes completos para llegar a una atinada conclusión y el peso específico vital del convencimiento de la persona que probablemente mejor conoce la historia reciente de los Balcanes, juzgamos interesante transcribir la reflexión de Del Ponte el 15 de febrero del 2007:

Se podrán preguntar porqué mi oficina está tan interesada en acceder al expediente personal y completo de Ratko Mladic. Por que el expediente puede hablar por sí mismo y demostrar que Mladic no era un lunático que fue a destruir Bosnia para satisfacer sus ideas locas. No. Era un alto oficial del ejército yugoslavo en misión en Bosnia como comandante de la VRS. Fue ascendido dos veces durante la guerra con las máximas calificaciones en su expediente, la completa aprobación de los militares de Belgrado y los líderes políticos y con una generosa remuneración. Si, por un momento, combinan esto con los hechos sobre el terreno, conocidos por todo el mundo y reportados a Belgrado, tenemos los hechos establecidos más allá de cualquier duda y es que Belgrado estaba directamente implicada en la guerra en Bosnia. ¿Y posteriormente? Belgrado organizó escondites confortables para Mladic en Serbia para que así pudiera escapar a la justicia 
internacional. ¿Y dónde está ahora? Todavía está en Serbia. Nada se hizo para parar ni castigar a Mladic y a sus asociados. ${ }^{3}$

\section{Del Ponte es muy clara al afirmar que}

Los archivos militares están cerrados para nosotros, incluso para las investigaciones en que los serbios son víctimas. La estrategia es clara y puede muy bien ser explicada por la afirmación hecha una sola vez y nunca más repetida por el gobierno de Belgrado de que ningún documento que comprometiera la posición de la República Federal de Yugoslavia ante la Corte Internacional de Justicia sería entregado al TPIAY, donde Bosnia y Croacia persiguen el pago de reparaciones. ${ }^{4}$

La corte mundial utiliza exclusivamente las pruebas y los argumentos que las partes le ponen delante. No persigue y presiona para obtener evidencias distintas o más profundas. Un escándalo se desató al conocerse que cajas de documentos confidenciales, que pudieran haber establecido ese enlace perdido y no demostrado para la Corte entre Serbia y lo ocurrido en Bosnia, fueron cercenadas, censuradas y eliminadas al ser trasladadas al TPIAY con el único objetivo, ya no tan secreto, de que cuando fueran utilizadas para el juicio de la responsabilidad estatal, los quince jueces mundiales no tuvieran toda la verdad frente a ellos. Ahora se descubre que los jueces de este tribunal penal sí tuvieron acceso al contenido íntegro de los documentos, pero autorizaron su censura para la posteridad. Y la posteridad era la responsabilidad o no de Serbia en el genocidio de musulmanes. Una cosa es que se juzgue la responsabilidad de un individuo concreto y otra es la responsabilidad de un gobierno o un Estado. La estrategia de defensa serbia era a largo plazo. Los serbios triunfaron.

La Corte Internacional de Justicia parte de un sistema acusatorio de valorar las pruebas que ante ella se presentan sin más pretensiones, ni intentos de convertirse en un sistema inquisitivo. Cumple con la llamada justicia rogada, es decir, la justicia solicitada es a lo que se atiene y el principio de jurisdicción voluntaria planea durante todo el procedimien-

3 Consultado en http://www.un.org/icty/pressreal/2007/cadelst-070215.htm.

4 Discurso de la entonces fiscal de los dos tribunales ad hoc de Naciones Unidas, TPIAY y TPIR, ante el Consejo de Seguridad el 30 de octubre del 2002. Su largo mandato finaliza en septiembre del 2007. El TPIAY cerrará sus puertas en el 2010. 
to, dejando a los contendientes un protagonismo exacerbado que nos lleva a pensar en un sistema de justicia arbitral donde las partes disponen a su antojo de todo el procedimiento, incluso nombrando a los árbitros. Afortunadamente los quince jueces están elegidos de antemano, aunque la figura del juez ad hoc se materializa cuando uno de los magistrados ostenta la nacionalidad de una de las partes.

El TPIAY, por el contrario, persigue sin descanso y sin diplomacias, su fiscal es uno de los personajes internacionales más sinceros, a las personas responsables de los más graves crímenes contra la humanidad. Los investiga, los detiene, los encarcela preventivamente, los somete a inacabables procesos, algunos mueren durante los mismos, como Milosevic, los sentencia en primera y segunda instancia, los condena a penas de cárcel y los remite a cumplir sus años a una prisión europea.

Son dos realidades distintas. Juzgaron los mismos hechos con pruebas plenas y pruebas cercenadas. No hubo o no se quiso que hubiera cooperación entre las dos. A pesar de la evidencia de todos los procesados y condenados previamente por el TPIAY, la CIJ no quiso ver a Serbia detrás de los horrores acontecidos a los musulmanes en Bosnia Herzegovina. Nunca quiso ser un órgano de justicia sino de pacificación en una zona milenariamente convulsa. Sacrificó el interés de la justicia en aras de una paz falsa, irreal sin herir supuestas susceptibilidades soberanas. Dejó el trabajo sucio pero necesario a los que realmente nacieron para llevarlo a cabo y, además, saben hacerlo. Sin embargo, quizás haya comprometido para siempre su credibilidad internacional. La posibilidad de una jerarquía entre los dos tribunales queda descartada por la sala de apelaciones del TPIAY al responder el 25 de mayo del 2001 a una acción interlocutoria del acusado Zoran Zigic $^{5}$ en contra de una decisión de 5 de diciembre de 2000, al no encontrar base legal para sugerir que existe una relación jerárquica entre ambos ni que el TPIAY esté legalmente obligado por las decisiones de la corte mundial. Añade y enfatiza que las decisiones de ésta que lidien con cuestiones generales de derecho internacional son de la máxima importancia y que el TPIAY las considerará y les otorgará el peso debido a su autoridad, negando que por ello deba suspender sus actuaciones hasta que la corte mundial se pronuncie. El presidente del TPIAY, Fausto Pocar, alabó ${ }^{6}$ la confirmación por parte de la

5 Consultado en www.un.org/icty/kvocka/appeal/decision-e/10525JN315907.htm.

6 Consultado en http://www.un.org/icty/briefing/2007/pb070613.htm. 
CIJ del genocidio de Srebrenica y la confianza demostrada por éste en la jurisprudencia del Tribunal que él preside.

La Corte de las Naciones Unidas ha dicho en derecho que Serbia no cometió genocidio, ni conspiró ni incitó a su comisión en Bosnia Herzegovina. Simplemente no lo previno en la matanza, recalificada por ella de genocidio siguiendo la estela marcada por el TPIAY, de ocho mil musulmanes en Srebrenica en 1995, por lo que también violó su obligación de cumplir con las medidas provisionales. No se puede demostrar más allá de toda duda razonable que hubiera un intento deliberado de destruir en parte o en todo a un grupo nacional, étnico, racial o religioso por parte de las autoridades yugoslavas. Ni siquiera Bosnia ha merecido reparaciones económicas, ya que no se pudo demostrar que de haber actuado Serbia para prevenirlo, la masacre de Srebrenica no hubiera tenido lugar. Se trata de dos pruebas diabólicas de dificilísima demostración. Croacia puede ir retirando su demanda. El alto tribunal onusiano no es el camino para establecer la verdad histórica. El super ministro de asuntos exteriores de la Unión Europea, Javier Solana, felicitó el sentido del fallo como utilitarista. Sus exactas manifestaciones, el mismo día que la sentencia devino pública, son un poema al entendimiento y a la reconciliación utilitarista, y reafirman el contenido político y la evidente solución equilibrada que quiso producir la Corte:

El veredicto de hoy del Tribunal de La Haya debe ser bien recibido. Nosotros lo aceptamos y creemos que contribuirá a cerrar los debates de una historia dramática que fue muy dolorosa y dañina para mucha gente. Espero que las partes concernidas en la región la acepten, la respeten plenamente e implementen todos los aspectos de la sentencia. Todavía no he estudiado la misma en detalle, pero sí hay una cosa que quiero destacar: No hay castigo colectivo. Es bueno que al final el más alto tribunal del mundo haya cerrado esta página y espero que esto ayude a la reconciliación final de los pueblos de los Balcanes. ${ }^{7}$

A propósito de Solana, no puedo dejar de transcribir las palabras de un periodista de guerra que cubrió el conflicto y luego se convirtió en uno de los escritores más reconocidos de habla hispana:

7 Consultado en http://www.consilium.europa.eu/ueDocs/cms_Data/docs/pressda ta/en/discours/92955.pdf (traducido del inglés por el autor). 
La abyecta cobardía de los holandeses ante los carniceros serbios, los tres mil prisioneros asesinados en Srebrenica tras la caída de la ciudad, la torpe indecisión de Naciones Unidas, la sonrisa injustificada, cobarde, del presunto negociador Javier Solana, prodigio de incompetencia que hoy sigue al frente de la política exterior de la Unión Europea, al que toda mi vida, y la suya, recordaré lavándose las manos en los telediarios o dándose besitos en la boca con los carniceros serbios, mientras quienes estábamos allí, grabando sangre y mierda, contábamos los muertos de cada día, con imágenes a las que ese paniaguado inútil oponía declaraciones huecas, afirmando con solemne gravedad de tonto del haba que, pese a las apariencias, los serbios se mostraban receptivos y razonables y que el asunto estaba en buenas manos. Y así día tras día, año tras año, mientras caían las bombas, se mataba y se violaba ante los ojos de una Europa miserable que nada hizo hasta que, tiene huevos quien paró la cosa, los Estados Unidos de Clinton decidieron, por fin, dar un puñetazo sobre la mesa. ${ }^{8}$

El último Alto Representante y Representante Especial de la Unión Europea en Bosnia Herzegovina, Christian Schwarz-Schilling, también coincide con que, permítanme el chascarrillo, el fallo es un acierto. ${ }^{9}$ Lo único destacable es la afirmación de que para la comunidad internacional, el veredicto ha reafirmado la obligación de prevenir el genocidio que los líderes políticos nunca deben olvidar.

La presidente de la CIJ tuvo que realizar una declaración aclaratoria cuando lo ético y lo esperable es que la sentencia hable por sí sola. En el mismo acto público en que se presentó el fallo, explicó ${ }^{10}$ detalladamente su sentido en lo que pudiéramos considerar el epítome del tópico: explicaciones no pedidas, acusación manifiesta. No nos resistimos a traducir y transcribir sus reveladoras palabras:

Las consideraciones judiciales han desembocado en resultados mixtos en cuanto a las partes corresponde. Esto no significa, desde luego, que la Corte haya buscado un compromiso político, menos aún un resultado pre-

8 Pérez Reverte, Arturo, "Fantasmas de los Balcanes", XL Semanal, núm. 1024, 10-16 de junio del 2007. http://www.xlsemanal.com/web/firma.php?id_edicion=2127\&id firma $=4150$.

9 Consultado en http://www.ohr.int/ohr-dept/presso/pressr/default.asp? content_id= 39313. Su mandato se ha extendido hasta junio del 2008, pero las fuerzas de la UE en Bosnia se han recortado de 6000 a 2500.

10 Consultado en $h t t p: / / w w w . i c j-c i j . o r g / i c j w w w / i p r e s s c o m / S P E E C H E S / i s p e e c h \_p r e$ sident_higgins_bhy_20070226.htm. 
determinado. Al basarse su jurisdicción en el consentimiento, y éste sólo se dio con respecto al artículo IX de la Convención de Genocidio, la Corte exclusivamente se puede pronunciar sobre este crimen a pesar de que tuvieron pruebas sustanciales de hechos ocurridos en Bosnia y Herzegovina que pudieran ser constitutivos de crímenes contra la humanidad o de guerra. Sólo genocidio y genocidio en el sentido legal del término, no en su sentido más amplio. El asunto acarreaba muchísimos hechos, se debía comprobar si las atrocidades alegadas ocurrieron y si así fue, si hubo un intento específico por parte de los perpetradores de destruir en todo o en parte al grupo protegido, identificado por la Corte como musulmanes bosnios. Este es el dolus specialis que se debe demostrar más allá de cualquier duda razonable y que distingue al genocidio de otros crímenes, constituyéndose en una auténtica prueba diabólica, además de que deben ser pruebas completamente determinantes. Aunque hicieron sus propias determinaciones de hechos basados en la prueba ante ella aportada, también se beneficiaron mucho de los hechos comprobados por el TPIAY cuando lidiaba con acusados particulares. Sólo con la excepción de lo que pasó en Srebrenica, las evidencias no demostraron que los terribles actos cometidos, matanzas masivas, infrahumanas condiciones de vida, fueran acompañados de la necesaria y especifica intención de destruir el grupo requerido para probar el genocidio. Aunque el demandante argumenta que esa específica intención puede ser inferida del patrón de atrocidades, la específica intención debe mostrarse convincentemente por referencia a circunstancias particulares. Unas determinadas conductas serán aceptadas como prueba de la existencia de genocidio si éste es la única explicación posible de la conducta concernida. Hubo una importante excepción. La Corte encontró que había pruebas suficientes y conclusivas que asesinatos y actos causantes de grave daño físico y mental contra musulmanes bosnios tuvieron lugar en Srebrenica en julio de 1995. Estos actos fueron dirigidos por el alto mando del ejército de la República de Srpska que tenía la específica intención genocida. Ahora la Corte debía decidir si Serbia era responsable legal por los actos de este ejército en Srebrenica al ser éste un órgano de Serbia y Montenegro u operar bajo sus instrucciones, su dirección o su efectivo control sobre las operaciones en que se perpetraron las masacres. La información presentada ante la Corte no era conclusiva, de hecho, todas las pruebas apuntan a que la decisión de matar a los hombres adultos fue tomada por algunos miembros del mando principal del ejército, sin instrucciones ni control efectivo por el ejército federal yugoslavo. La complicidad en la Convención sobre Genocidio exige que el demandado provea medios que hagan posible o faciliten los hechos de Srebrenica con plena consciencia que la ayuda suministrada sería usada para cometer genocidio. Una vez más este es el elemento que falta. Como el demandado no ha sido hallado 
por la Corte como autor ni responsable del genocidio de Srebrenica, las reparaciones masivas quedan fuera de lugar. En cuanto a la violación de la obligación de evitar genocidio, la Corte considera, tal y como el demandante sugirió, que una declaración de la Corte es en sí misma apropiada satisfacción. Existe para la Corte una violación continuada de la obligación de Serbia de castigar el genocidio que debe de terminar de inmediato, además de transferir a los individuos acusados de genocidio para que los enjuicie el TPIAY con el que debe cooperar plenamente.

Condenar a alguien por genocidio o complicidad en el mismo es muy complicado, incluso para los tribunales internacionales específicos dados a la tarea. Probar la intencionalidad es una prueba que a veces resulta insuperable.

El término genocidio, acuñado en 1944 por Raphael Lemkin, un polaco judío refugiado en Estados Unidos de América y consejero del Secretariado de Guerra estadounidense, deriva del griego genos que significa raza y del sufijo latín cide de caedere, matar. El mismo TPIY, que tipificó la masacre de Srbrenica como genocidio, sólo ha condenado por complicidad en el genocidio a dos responsables de las milicias serbias, Krstic y Blagojevic. Incluso en este último caso, la sentencia de apelación de 9 de mayo del 2007 del TIPAY, aceptando el recurso planteado por el sentenciado, ${ }^{11}$ anula la condena por el cargo de complicidad en genocidio, reduciendo la pena de prisión de dieciocho a quince años. El sentenciado negaba su conocimiento de la comisión del crimen de genocidio, de los asesinatos masivos y del intento de genocidio de sus principales perpetradores. La sala de apelaciones acepta que el traslado forzado, la separación, los maltratos y asesinatos cometidos en la ciudad de Bratunac, son hechos relevantes para valorar la existencia o no de la intención genocida de los principales perpetradores, pero no para demostrar su intención de destruir al grupo protegido. Compartimos la crítica del gran juez internacional Antonio Cassese, según la cual, el que "las personas acusadas de genocidio [que] deberán ser juzgadas por un tribunal competente del Estado, en cuyo territorio el acto fue cometido, es una garantía puramente platónica al igual que la necesidad de probar que los mismos han sido perpetrados con la intención de aniquilar un grupo".

11 Consultado en http://www.un.org/icty/indictment/english/blajok-jud070509.pdf. 
Por otra parte, la entidad serbia de Bosnia con el nombre difícilmente pronunciable de República de Srpska, otorgó su consentimiento fulgurante e interesado, apenas cuarenta y ocho horas después de pronunciada la sentencia en forma de disculpa oficial ${ }^{12}$ a las víctimas de la guerra, expresando su más hondo pesar por los crímenes cometidos contra no serbios y condenando a todas las personas que participaron en su comisión.

Ruth Wedgwood, ${ }^{13}$ destacada profesora de derecho internacional, critica duramente esta sentencia con argumentos apegados al derecho. Sus ideas básicas sobre el derecho internacional y la política exterior estadounidense coinciden milimétricamente con el presidente G. W. Bush. Desde temas tan sensibles como la Corte Penal Internacional y la Opinión Consultiva sobre la Legitimidad Internacional del Muro de Israel emitida por la Corte que analizamos, sus opiniones podrían ser suscritas a ciegas por la secretaria de Estado, Rice. En un artículo ${ }^{14}$ publicado apenas dos semanas después de la sentencia, el título no deja lugar a dudas, "Un mal día para la justicia internacional". Opina que este caso civil internacional nunca debiera haber terminado en sentencia si su resultado iba a ser tan pobre. No entiende por qué las matanzas deliberadas de civiles en la ciudad de Brcko en 1992 o la tortura y hambruna infligidas a los civiles musulmanes de Foca, son de un tipo diferente a los asesinatos de Srebrenica calificados por la CIJ como genocidio. Las implicaciones de la sentencia conforman una póstuma liberación de culpa genocida de Milosevic en Bosnia. Insiste en que a menos que Belgrado dé órdenes directas para operaciones especiales o que los serbio bosnios fueran completamente dependientes de Belgrado, no existe responsabilidad, lo que llamará seguramente la atención de los doctrinarios del common law que están acostumbrados a que la responsabilidad por mala práctica puede ser compartida. La CIJ aplica los requisitos de prueba criminal a casos civiles, al insistir los jueces que incluso para responsabilidad civil, la prueba contra Belgrado debe ser completamente concluyente e incontrovertible con un nivel de certeza más allá de toda duda. Además está la incoherencia o el doble rasero o estándar aplicado cuando fue desestimada

12 Consultado en http://www.nytimes.com/2007/03/01/world/europe/01briefs-serba pology.html?_r=1\&oref=slogin.

13 Directora del Programa de derecho internacional de la Escuela para Estudios Internacionales Avanzados de la Universidad Johns Hopkins de Washington, DC.

14 Consultado en http://www.iht.com/articles/2007/03/08/opinion/edwedge.php (traducido al español por el autor). 
la demanda de Serbia contra varios países de la coalición de la NATO ${ }^{15}$ que intervino en Kosovo con el argumento de que Yugoslavia no era ya un miembro de Naciones Unidas, y por lo tanto no tenía derecho de acceso a la Corte, mismo argumento que debiera haber prevalecido en este caso cuando era demandado.

Precisamente en una opinión ${ }^{16}$ de esta autora sobre el muro de Israel, a propósito de la Opinión Consultiva de la Corte, curiosamente calificada como valla, fence, en lugar de muro, wall, ${ }^{17}$ aprovecha para criticar con dureza los tribunales internacionales en general y el de Naciones Unidas en particular. Argumenta la escasa capacidad para investigar que tiene la Corte al carecer de una sala específica previa denominada sala de primera instancia que pueda investigar el itinerario de la valla, la adecuación de las puertas de acceso y la disponibilidad de otras maneras de controlar a los suicidas palestinos. Las cortes internacionales juzgan en medio de una estructura anárquica y relaciones desordenadas en donde el poder todavía cuenta, donde los intereses en juego pueden ser muy importantes, tales como la defensa de un Estado frente a sus enemigos o el mantenimiento de una viabilidad económica mínima. Al no tener una fuerza policial propia que ejecute sus sentencias, lo apropiado es que se limiten a juzgar, cuando las partes han aceptado que el contencioso se ventile en esa instancia y van a acatar su resultado. La costumbre internacional es casi siempre la única fuente de derecho disponible, en eterno proceso de cambio, descartando los tratados siempre antiguos. Aboga por que la Corte no siga adelante con las audiencias que en ese momento tenían lugar en La Haya, con la ausencia calificada por ella de conspicua de los Estados grandes, ya que interferiría con la hoja de ruta, el desafío implícito a la autoridad del Consejo de Seguridad, la parcialidad de sólo tener en cuenta una parte de los derechos humanos y la carencia de poderes de investigación.

Afortunadamente, y después de una importante presión internacional, se rechazó que el presidente del nuevo Parlamento de Serbia fuera

15 Consultado en http://www.icj-cij.org/docket/index.php? $p 1=3 \& p 2=3 \&$ code $=y u s \&$ case $=114 \& k=25$.

16 Consultado en $h t t p: / / w w w$. benadorassociates.com/pf.php? $i d=2222$, el 23 de febrero del 2004, como parte de un libro blanco sobre el tema.

17 Consultado en http://www.icj-cij.org/docket/files/131/1671.pdf. Legal Consequences of the Construction of a Wall in the Occupied Palestinian Territory. Conséquences juridiques de l'édification d'un mur dans le territoire palestinien occupé. 
un dirigente del partido radical serbio, del actualmente juzgado ante el TPIAY por crímenes de guerra, Vojislav Seselj. Un signo altamente positivo hacia la vuelta a la plena cooperación de Serbia con el TPIAY, paralizada durante 2006 y 2007, lo constituye un discurso ${ }^{18}$ del ministro de asuntos exteriores serbio en el que textualmente declara:

Un componente crucial en la construcción de Europa sin divisiones es la reconciliación. La democracia no puede florecer sin una plena y abierta rendición de cuentas del pasado. Es por esto por lo que la República de Serbia se encuentra fuertemente comprometida en una total e inmediata cooperación con el TPIAY. Todos los procesados deben ser localizados, arrestados y extraditados. No es simplemente nuestra obligación internacional, sino además nuestro deber moral para nuestros vecinos, el mundo y para nosotros mismos.

A raíz de este cambio de actitud, avalado por la detención en mayo de 2007 en Serbia del serbobosnio Zdravko Tolimir, uno de los seis acusados por crímenes de guerra que permanecía huido, las congeladas negociaciones con Serbia para acceder a la Unión Europea se han retomado en junio del 2007.

El prestigio de la CIJ, a juzgar por el número de casos que recibe, no está dañado. Este tipo de sentencias puede hacerlo. Si además sumamos trabajos profundos sobre la parcialidad, no consciente, de los jueces que lo conforman, el futuro no se ve diáfano. En un estudio ${ }^{19}$ en el que se utilizan métodos estadísticos, pruebas contundentes revelaron que los jueces favorecen a los Estados que los proponen en nueve de cada diez casos y a los que gozan de un nivel de vida semejante al de los Estados de que son nacionales. Son más ecuánimes cuando las dos partes son muy similares a su país de origen o muy diferentes. Este mismo autor publicó en el New York Times un artículo titulado "La Corte Internacional en declive", ${ }^{20}$ en el que afirma que "desde su creación hace sesenta años, la

18 Pronunciado por Vuk Jeremic ante el Comité del Parlamento Europeo reunido en Belgrado el 24 de mayo del 2007. http://assembly.coe.int/ASP/APFeaturesManager/de faultArtSiteView.asp? ID=676.

19 Posner, Eric A. y Figueiredo, Miguel de, "Is the International Court of Justice Biased?", Olin Working Paper, U. Chicago Law \& Economics, núm. 234, diciembre de 2004. Consúltese en http://papers.ssrn.com/sol3/papers.cfm?abstract_id $=642581$.

20 El 13 de enero del 2005. 
CIJ es impotente porque no logró adaptarse a las políticas del poder, cuando desaparezca quizás lo podamos hacer mejor".

No eran necesarias grandes alforjas para un viaje largo que iba a tener un resultado tan nimio y un camino tan exiguo para el derecho internacional. La Corte ha demostrado, muy a muestro pesar, que su naturaleza es más política que judicial.

Nos resultó excepcionalmente útil las páginas oficiales de Internet de los diferentes tribunales internacionales, ya que permiten el acceso a cualquier sentencia desde cualquier parte del mundo. 